\title{
SELF LEARNING COMPUTER TROUBLESHOOTING EXPERT SYSTEM
}

\author{
Amanuel Ayde Ergado \\ Department of Information science, Jimma University, Jimma, Ethiopia.
}

\begin{abstract}
In computer domain the professionals were limited in number but the numbers of institutions looking for computer professionals were high. The aim of this study is developing self learning expert system which is providing troubleshooting information about problems occurred in the computer system for the information and communication technology technicians and computer users to solve problems effectively and efficiently to utilize computer and computer related resources. Domain knowledge was acquired using semistructured interview technique, observation and document analysis. Domain experts were purposively selected for the interview question. The conceptual model of the expert system was designed by using a decision tree structure which is easy to understand and interpret the causes involved in computer troubleshooting. Based on the conceptual model, the expert system was developed by using 'if-then' rules. The developed system used backward chaining to infer the rules and provide appropriate recommendations. According to the system evaluators $83.6 \%$ of the users were satisfied with the prototype.
\end{abstract}

Keywords: expert system, computer troubleshooting, self learning, knowledge based system

\section{INTRODUCTION}

Computer systems (hardware, software and network connection) face problems from time to time and endanger the functionality of the institutions. These problems need Information and Communication Technology (ICT) technicians to be solved. The ICT technicians follow traditional (manual) ways of solving computer problems which is taking long time and high cost to reach the solution.

An intelligent system is one component of an artificial intelligence which is working like human expert but it cannot replace human expert. It supports human experts in making decision, i.e., it acts in all respect of human counterpart. Sometimes interchangeably used as knowledge-based system and is computer software which makes decision like a human expert [1,2]. The benefit of intelligent system above traditional programming language is it does not depend on the code instead the data is stored in different location called knowledge base. Due to this reason, intelligent systems are not required to be programmed as the domain knowledge changes from time to time or from expert to expert knowledge. In real situation intelligent systems are applied in different decision making process from medical activities to intelligent decision making purpose [3].

This Self Learning Computer Troubleshooting Expert System (SLCTES) helps a user to search solution with specific answer for the specific problem. This SLCTES was designed to indicate 
International Journal of Artificial Intelligence \& Applications (IJAIA), Vol. 7, No. 1, January 2016

appropriate troubleshooting for maintenance, fault indication, and accessing the knowledge base [4]. The computer troubleshooting expert system presents the technician with a list of guiding questions, when answered; provide the system with information about what problem sets the issue may belong to, and which ones it does not belong to. It then generates another list of questions that apply to subsets of those identified questions. After finding specific causes the system provides possible troubleshooting mechanism for the technician. This process can save time, energy and cost through by saving the current list of questions and possible solutions [5].

There are a number of different approaches for designing knowledge based system but this self learning computer troubleshooting expert system focused on rule based approach. According to pira et al. [6] "a rule base is the central part of an expert system that extracts the knowledge from domain experts in the form of inference rules. Structural errors usually appear by augmenting the knowledge base rules. The typical types of structural errors include confliction (conflict rules), unreachability(unreachable rules), subsumption (subsumed rules), redundancy (redundant rules), and circularity (circular depending rules)."

This self learning expert system has ability to make computer troubleshooting process automatic and help ICT professional to find the cause within few seconds, save energy and financial cost in fault maintaining process. Computer components are classified basically into two: such as hardware and software. The hardware itself classified into different specific components and software is also classified into application software and system software. These components may face problems due to different reasons. Troubleshooting faced problems in manual way is not suitable and simple. To make the problem solving more simple and appropriate intelligent system is very essential because it have ability to find faults and suggest appropriate solutions based on the knowledge stored in the knowledge base. Depending on the questions issued by the user or ICT technician the system looks its knowledge base and then responds the questions and lastly suggests possible solution for the problem occurred in the computer system. The SLCTES have ability to indicate its reasoning mechanism [7]. This expert system has also self learning ability to handle new problems occurring in the computer system and their respective solutions [8].

\section{PROBLEM STATEMENT}

Each computer parts have its own troubleshooting mechanisms to assure its integrity in the time of problem occurrence in the computer system. But, there are limited numbers of troubleshooting resources and standardized maintenance strategies to find out the problem in general level or specific maintenance level. Therefore, fetching out one or more problems occurred in the computer component is challenging task for the ICT technician. The ICT professional is educated to use this limited number of troubleshooting resources to maintain computer components problem specifically, due to this solving the problem is not simple task for the technician. To solve the problem of limited number of troubleshooting resources and to support ICT technician skill expert system support is crucial. By using the intelligent system, the required time and cost for identification of fault and repairing the fault is decreased [7]. According to Mandal, "the demand for higher availability of production systems to have a cost-effective distribution of fixed assets and to minimize manufacturing delays due to machine failures caused by unplanned downtimes. Unplanned downtime increases the maintenance costs and reduces productivity. The manufacturing units may cancel customers or delay, as it happens regularly, the preventative maintenance project days in not advance" [4]. 
International Journal of Artificial Intelligence \& Applications (IJAIA), Vol. 7, No. 1, January 2016

As the researcher's knowledge, there are no local researches in self learning computer troubleshooting expert system but there are international works in the area. Those international works advice computer users and experts how to solve problems occurred in the computer system.

\section{OBJECTIVES}

The objective of the study is to develop self learning computer troubleshooting expert system which enables users to perform computer troubleshooting so as to utilize computer and computer related resources effectively and efficiently. Specifically:

- To acquire the required knowledge from the human expert, documents and observation

- Modeling and representing the tacit knowledge in a suitable way for knowledge based expert system implementation

- Designing the prototype self learning computer troubleshooting expert system

- Measuring the performance of the designed expert system

\section{SCOPE}

For designing expert systems, a number of approaches are available but this self learning computer troubleshooting expert system used rule based approach. The system learns new cases of the problem and provides support for decision making. There are different problems related to computer system but including all maintenance issues influence the system performance. Due to this reason this study focused on basic hardware problems, software (power problem, storage, compatibility and fixing) problems.

\section{LITERATURE REVIEW}

The core of expert system is developed from the field of artificial intelligence. The way of representing domain knowledge and the reasoning mechanisms are the reasons to bring domain experts knowledge into existence. Also they are very crucial part of artificial intelligence because they handle behaviors difficult to handle by other mechanisms [9].

Expert system (ES) and knowledge based systems (KBS) are synonym terms used in machine learning [10]. KBS is one of the major family members of the AI group. Expert systems have ability to act as human expert and it is used on demand without waiting long time and any place for maintenance. KBS can save money by leveraging human expert, allowing users to function at higher level and promote consistency of work. Some domain experts take expert system as helpful and productive because it has ability to store the knowledge of different experts for longer time. In reality, expert systems are computer dependent systems they capture and store domain expert's knowledge [11].

The following figure shows the building blocks of expert system architecture which is adopted from [12]. 


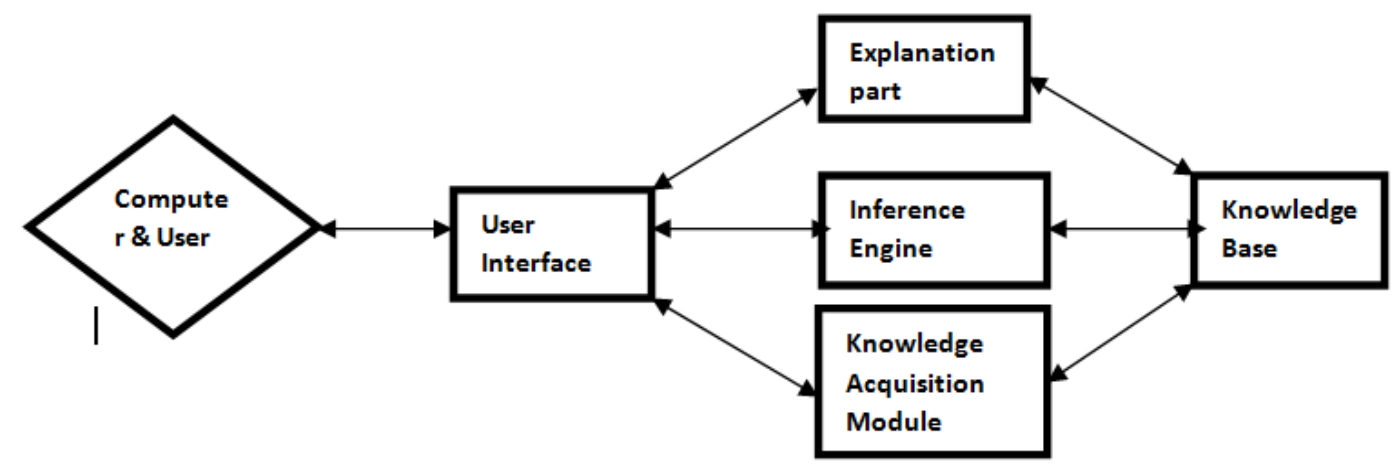

Figure 5.1 Architecture of knowledge based system

\subsection{The expert system Designing Process}

The development of expert system is the integration of many components. Figure 5.2 below shows the overview of expert system designing stages [10].

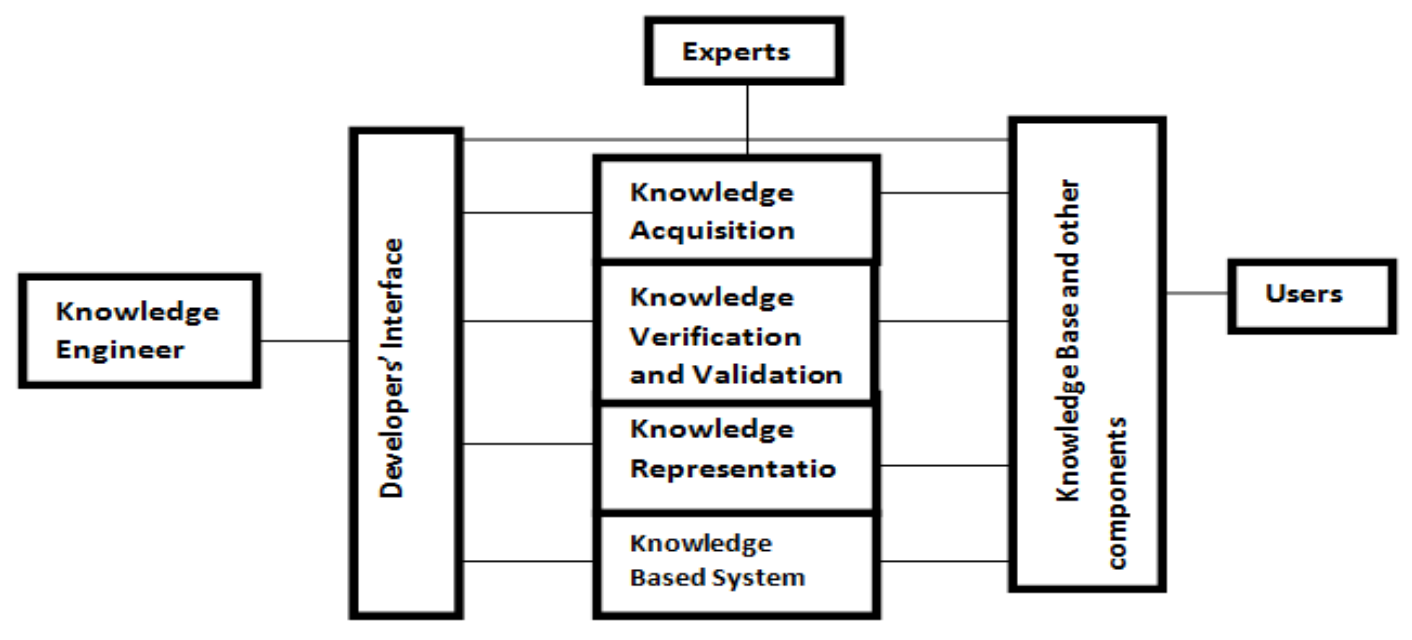

Figure 5.2 Expert System designing process

\subsection{Knowledge Based Reasoning Techniques}

In the designing process a lot of knowledge based reasoning mechanisms are there. The wellknown reasoning approaches are ontology based reasoning, case based reasoning and rule based reasoning. For the purpose of this research work, a rule-based reasoning approach was discussed as follows: 


\subsubsection{Rule Based Reasoning}

One of the approaches used in knowledge based reasoning technique is rule based reasoning (RBR) approach which is a system whose knowledge representation involves a set of conditions [13]. Symbol dependent rules are the most known reasoning methods and this popularity is mainly due to their naturalness, which facilitates comprehension of the represented knowledge. The basic forms of a rule, If<condition> then <conclusion> where <condition> represents premises and <conclusion> represents associated action for the premises. The conditional statements of the reasoning rules are linked with each other by using logical operators to generate logical functionalities. When sufficient conditions of a rule are satisfied, then the conclusion is derived and the rule is said to be fired. Rule based reasoning was dominantly applied to represent general knowledge. Rule based expert systems have a significant role in many different domain areas such as computer maintenance, medical diagnosis, electronic troubleshooting and data interpretations. A typical rule based system consists of a list of rules, a cluster of facts and an interpreter [13].

Rules: the rules in the knowledge base are representing what should be done and what should not be done while some conditions are fulfilled. In the same way, the knowledge acquired from domain experts stored in the knowledge base as rules [14]. Generally, the rules are presented as follows [15].

IF

First premise, and

Second premise, and

Third premise, and

THEN

$\cdots$

Conclusion will be drawn

In the rule based system left side and right side is available so that, the left side indicates the conditions and the right side or the THEN side handle rules. Semantically the above description is the same as a Prolog rule:

Conclusion:- first_premise, second_premise ...

Previous circumstances are measured depending on what is known about the problem solved before. This mean if all antecedents (premise) of the rule evaluated is true, the actions in the consequents part is executed. Each predecessor of a rule specifically looks the given problem instance that satisfies the given conditions. When the consequents of the rules are executed, the rule is said to be fired [16].

\subsubsection{Rule Based Reasoning Techniques}

There are two main inference methods in rule based reasoning mechanism. These are backward chaining and forward chaining. The first one is leaded by the given goals or conclusions, whereas the second one is guided by the given facts [13]. For this study backward chaining was used to check whether the goal is succeed or not. 
International Journal of Artificial Intelligence \& Applications (IJAIA), Vol. 7, No. 1, January 2016

\subsubsection{Knowledge Based System Implementation Tools}

Lou Maher indicated "Three languages, OPS5, SRL, and PROLOG, were discussed by implementing an engineering design paradigm. A simple problem was chosen to illustrate various features of these languages; the problem itself could have been easily coded in FORTRAN or any other procedural language. The three languages were chosen to illustrate different representation formalisms - rules, frames, and logic - commonly used in the development of expert systems. While OPS5 and PROLOG provide the user with a primitive inference mechanism, SRL requires the user to write the inference mechanism in LISP; it was easier to implement the example in OPS5 and PROLOG than in SRL. However, the inheritance mechanism provided in SRL is very useful for implementing the hierarchical design process [17]."

\subsection{Related Research Works}

Sylvester and his colleague introduced a computer troubleshooting system depending on the problems based on intelligent system. The system is developed to detect hardware fault detection in any computer system. Various hardware, software or electronic resources challenged by application problems similarly hardware problems. The paper focused on automating the system which has ability accept the fault of systems and looks the intelligent database for probable solutions or recommendations [18].

DART: is a system which is giving advisory service for IBM field technician; on troubleshooting computer installation problem. The system finds out individual components problem in hardware or software and provides recommendation for main problems and adds causes that indicate the problem. DART was designed by using HMYCIN. It is huge finding for troubleshooting computer fault diagnosis. The DART knowledge base consists of 300 EMYCIN causes and 190 rules. It was developed for more than 8 months. $50 \%$ of diagnostic processes were correctly responded from online exploration [19].

Development in modern technology supported system designers to develop an automatic computer fault troubleshooting systems for enterprises in the near future. The system involve easy communication interface for the users and apply different expert system development approaches. The system has ability to detect Power-On-Self-Test beep sound errors and intelligent part which support in acquiring the knowledge from the domain experts. This system is a mechanism for automating computer troubleshooting process and support human technician in troubleshooting process [20].

The study conducted by Khayut [21] reveled that "IUI function is to facilitate the user to perform analysis, planning, decision-making, management and coordination of organizational unit. Under the facilitating in IUI is understood the full use of intelligence of the system to perform these and other functions by interacting with it in natural and/ or other language. In this regard, the function of the IUI should be based on the perception, processing and synthesizing knowledge in real time. The results of the work focused on the creation multi-agent IUI for multilingual interaction in autonomous, situational, intelligent, multi-agent information control systems of robots, unmanned production and spacecrafts and others, functioning in the fuzzy environment and unforeseen situations in advance." 
Pohronská [22] tried to develop schemes for embedded intelligent system, by determining the form of knowledge-base suitable for embedded intelligent systems. He developed a tool for automatic creation of system architecture from intelligent database and he stated shortest rules insisting the decision on the embedded intelligent [expert] systems implementation method selection.

The system designed by Golański and Mądrzycki [23] presented the concept of using expert methods for M-28 aircraft maintenance. It used CLIPS intelligent system development language like $\mathrm{C}$ language. This system evaluated by using expert systems evaluation technique on simple maintenance steps of M-28 aircraft. The encouraging result of the evaluation showed appropriate improvement of the intelligent database is possible in building a fully functioning troubleshooting system for the M- 20 aircraft.

\section{KNOWLEDGE ACQUISITION AND CONCEPTUAL MODELING}

Knowledge acquisition (KA) is the process of acquiring relevant knowledge from domain experts and other sources of information such as books, databases, guidelines, manuals, journal articles and computer files. KA is the process of eliciting, structuring and representing (formalizing) domain knowledge acquired from different sources. The term knowledge acquisition and knowledge elicitation have been used interchangeably in the field of artificial intelligence (AI) literature. The collected knowledge from the domain experts is specific to the fault, the fault may be whole or simply it is describing about the knowledge. Knowledge acquisition is the first step and time consuming task in the development of knowledge based system [24].

The objective of knowledge acquisition is to gather the required knowledge, interpreting the acquired knowledge, analyzing and validating the knowledge content. Based on the acquired knowledge, the KBS was designed using decision tree model.

Therefore, knowledge acquisition process of this thesis was based on domain expert interviewing, observing and reviewing of related documents.

\subsection{Interviewing Domain Experts}

Primary sources of knowledge were acquired from human experts in the domain area at Addis Ababa University ICT office. Four (4) domain experts were selected using purposive sampling technique. These experts were selected due to their managerial position and experience in the ICT office.

During the extensive discussion, the researcher acquired the relevant knowledge which was significant to generate the rules. In addition, the domain experts were actively participated throughout the research work and they were consulted to confirm the correctness of the acquired knowledge. Profiles of domain experts participated in the interview process were presented in the Table 6.1 below: 
International Journal of Artificial Intelligence \& Applications (IJAIA), Vol. 7, No. 1, January 2016

\begin{tabular}{|l|l|l|l|l|}
\hline No & Educational level & Specialization & Area interviewed & Position \\
\hline 1 & PhD. & ICT & Computer and network & ICT director \\
\hline 2 & Msc. & ICT & Network & Network administrator \\
\hline 3 & Bsc. & ICT & Computer & ICT technician \\
\hline 4 & Bsc. & ICT & Computer & ICT technician \\
\hline
\end{tabular}

Table 6.1: Profiles of domain experts

\subsection{Observation and Document Analysis}

To find additional information in addition to interview questions, observation and document analysis was used when the human expert is troubleshooting the problems occurred in the computer system and guidelines used for troubleshooting were analyzed.

\subsection{Conceptual Modeling}

In modeling expert systems knowledge base there are different modeling techniques; one of them is Decision tree. It is used in different settings to order and classify data for conceptual modeling [25]. They are the bases for the development of self learning computer troubleshooting expert system. The expert system follows the same procedures as presented in the decision tree when diagnosing computer problems. Some of the causes were modeled by using decision tree as follows:

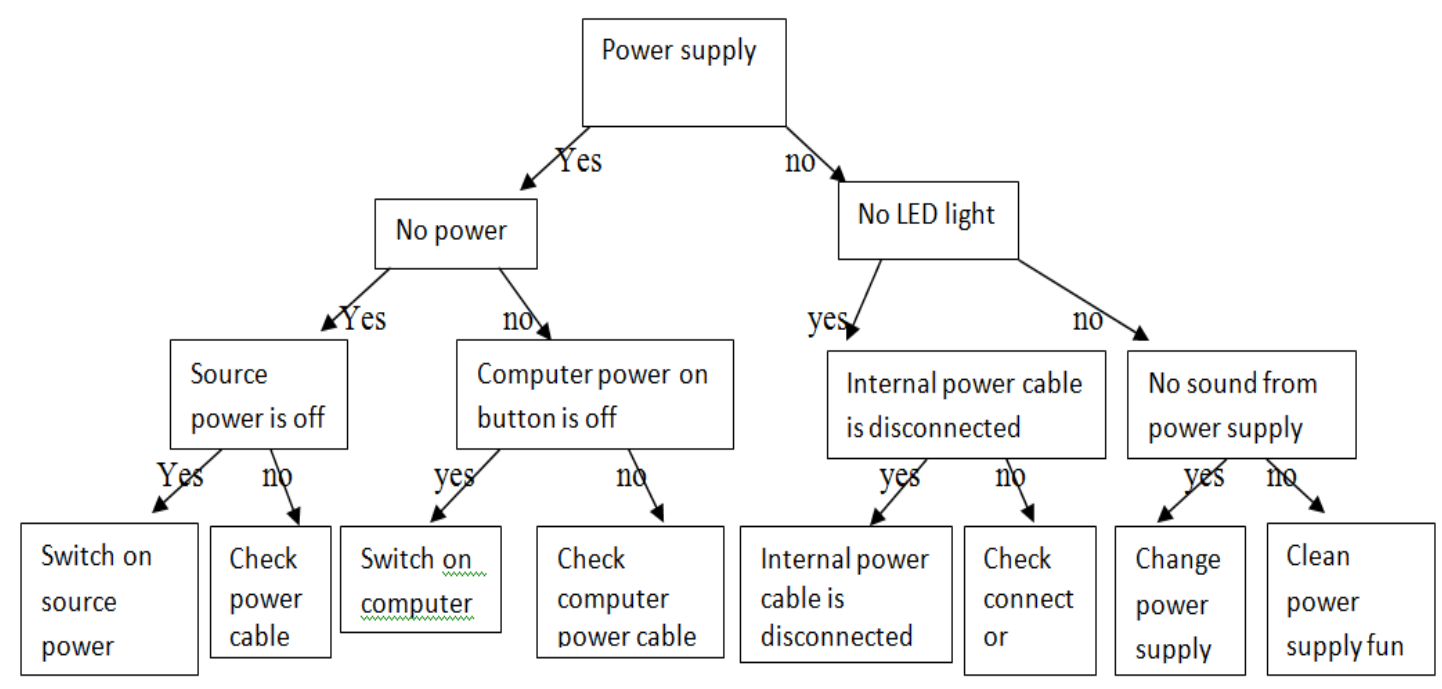

Figure 6.1 Decision tree for power supply problem 


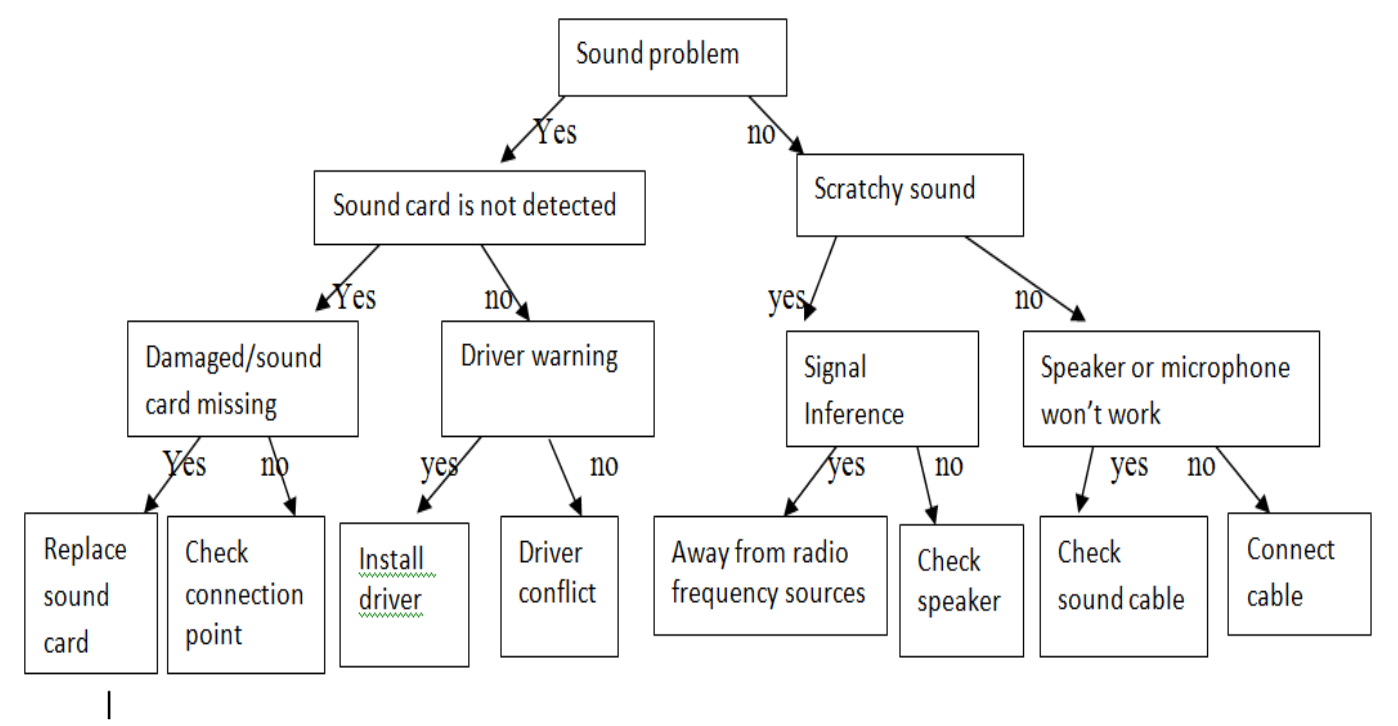

Figure 6.2 Decision tree for sound problem

\section{KNOWLEDGE REPRESENTATION}

Representing acquired domain knowledge is one of the core stages in the steps of intelligent system development cycle. Knowledge representation is the process of interpreting domain knowledge into computer understandable form by using knowledge representation methods.

The collected expert's knowledge is represented as a set of conditions which have facts and rules in the intelligent database. Rules in the knowledge base were constructed based on the decision tree structure on conceptual model discussed above.

To make easy and understandable prolog rules, the acquired knowledge from the domain experts represented using the "IF-THEN" form. The rules are the base for the construction of KBS. The following are sample rules which are incorporated in the knowledge base.

If the computer has no power,

The power source And/Or the computer power On button is off,

Then switch On source power And/Or switch On your computer.

If the computer has no LED light,

The internal power cable is disconnected,

Then connect the internal power cable.

If there is no sound from the power supply, Damaged fuse And/Or damaged power supply,

Then change the power supply.

If the hard disk drive specification error, Similar procedures have been used for all rules incorporated in the knowledge base.
Drive has not been formatted, Then run FDISK to create partition. If SMART warning displayed, Serious mechanical problems are detected,

Backup and replace your drive.

If hard disk drive type error,

The drive not formatted,

Then format the drive.

If no drive,

Power cable is disconnected,

And/Or data cable is disconnected,

Then connect,

Data cable And/Or power cable. 


\section{IMPLEMENTATION}

The most important criterion for any expert system is the accuracy of their inference engines. Also robustness of the system is very important when some information is missing, redundant and inconsistent. Human readability helps the domain experts to understand knowledge content and even to modify its content. The system's dynamic nature to adopt a new knowledge from the user response is critically important to measure system performance. When implementing the self learning computer troubleshooting expert system the conceptual modeling was used as its core. The if-then rules of SLCTES are generated based on the decision tree structure.

The expert system designed for SLCTES incorporated knowledge base, inference engine, learning component, user interface, and explanation facility components as shown in figure 8.1.

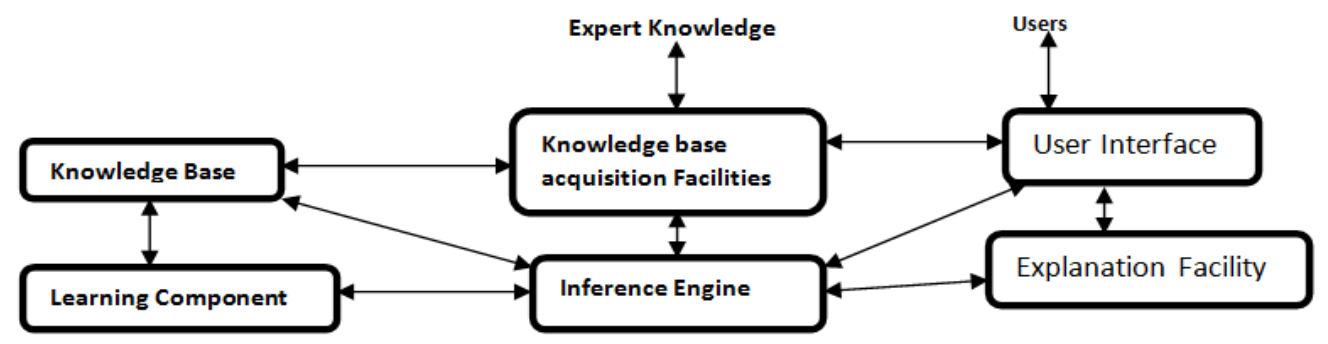

Figure 8. 1. Architecture of rule based system

\section{TESTING AND EVALUATION}

In this study the performance of the system was measured against human expert decision using predictive validation method. The user acceptance of the system was carried out during system user interaction. The expert system user acceptance was measured by using open and close ended questions. The system evaluators directly interact with the system to measure its performance from the points of its correctness in providing solutions for different problems.

The system performance evaluation was carried out by using questionnaires. Totally fifteen evaluation questions were prepared for 10 (ten) system evaluators. Questions used for system evaluation are divided into two: open and close ended questions. These questions are used to collect feedback from the system evaluator's depending on the system's solution/suggestion/recommendation. The following table 9.1 summarizes the results obtained from the respondents.

\begin{tabular}{|l|l|l|l|l|l|l|l|l|}
\hline No & Questions & $\mathbf{1}$ & $\mathbf{2}$ & $\mathbf{3}$ & $\mathbf{4}$ & $\mathbf{5}$ & $\mathbf{A v g}$ & $\begin{array}{l}\text { Total } \\
\text { Perf. }\end{array}$ \\
\hline 1 & Is the SLCTES system is efficient in time? & 0 & 0 & 1 & 5 & 4 & 4.3 & 86 \\
\hline 2 & What is the accuracv of the expert svstem? & 0 & 0 & 2 & 4 & 4 & 4.2 & 84 \\
\hline 3 & $\begin{array}{l}\text { Does the system incorporate sufficient knowledge to } \\
\text { solve problems? }\end{array}$ & 0 & 0 & 0 & 6 & 4 & 4.4 & 88 \\
\hline 4 & Does the system update its knowledge base? & 0 & 0 & 1 & 5 & 4 & 4.3 & 86 \\
\hline 5 & $\begin{array}{l}\text { What is the contribution of the system in the domain } \\
\text { area? }\end{array}$ & 0 & 0 & 3 & 7 & 0 & 3.7 & 74 \\
\hline & \multicolumn{3}{|l|}{ Total average } \\
\hline
\end{tabular}

Key: 1= poor, 2 = fair, $3=$ good, $4=$ very good, $5=$ excellent

Table 9.1. Performance evaluation 
When summarizing table 9.1 above, based on the responses of ten system evaluator, the average performance obtained is 4.18 on a scale of 5. This value is the result obtained from the values assigned for each close ended question. The result indicated that about $83.6 \%$ of users were satisfied by the performance of the expert system. It means that the expert system gained about $83.6 \%$ of user acceptance.

\section{DISCUSSION}

The prototype Self Learning Computer Troubleshooting Expert system is promising and applicable in the domain area. The results and recommendations of expert evaluators indicated that SLCTES got very good acceptance. The system acceptance evaluations used open and close ended questions to directly interact with system.

The table 10.0 below shows the summary of system performance evaluation result obtained from close ended questions.

\begin{tabular}{|l|l|l|l|l|l|l|}
\hline $\begin{array}{l}\text { Domain experts } \\
\text { responses }\end{array}$ & $\begin{array}{l}\mathbf{1}(\text { poor } \\
\text { ) }\end{array}$ & 2(fair) & 3(good) & 4(v. good) & 5(Excellent) & $\begin{array}{l}\text { Total Avg/ } \\
\text { Prf.\% }\end{array}$ \\
\hline Total number & 0 & 0 & 7 & 27 & 16 & 418 \\
\hline Average out of $100 \%$ & 0 & 0 & $14 \%$ & $54 \%$ & $32 \%$ & 83.6 \\
\hline
\end{tabular}

Table 10.0 system evaluators Result on Close Ended Questions

As the table 10.0 above indicated, based on system performance gained from user's visual interaction with the prototype expert system using the close ended questions; There is no evaluators respond as poor and fair, evaluators responded good fourteen times (14.2\%), very good fifty four times (54\%) and excellent thirty two times (32\%). The total average user acceptance evaluation result of SLCTES is about $83.6 \%$. This result shows that more than $83 \%$ users accepted the correct decision, knowledge content, learning ability, contribution and significance of the knowledge based system. Therefore, the prototype SLCTES satisfactorily makes the right decisions and providing appropriate recommendation during computer troubleshooting process.

The system evaluators were also provided open ended questions to collect expert's feedback, suggestion and opinions. These questions focus on how the SLCTES is different from human expert in diagnosing computer problems. Furthermore the open ended questions help evaluators to provide their feedbacks on the contributions of the system, the uncovered knowledge issues, knowledge content of the system, the limitations and strength of the knowledge based system.

The result of open ended questions indicated that:

- SLCTES solve problems based on the stored knowledge in the knowledge base with in time and cost wise. But, the human expert uses their expertise, vital signs, experience, manuals and guidelines which is time consuming and difficult to remember

- The expert system is efficient to respond from the stored knowledge in the knowledge base. Therefore, the knowledge base contains relevant knowledge for the selected 
problems to make the decision. But, some respondent argue that knowledge base system will not replace the function of human expert.

- As far as the knowledge base contains all the relevant knowledge acquired from the domain expert, the knowledge based system provides similar decision as human expert. Even the system can be considered more flexible due to its reusability of the existing knowledge in a better way than the human experts.

- System contains adequate knowledge for all rules incorporated in the knowledge base. As their suggestions indicated, the system must update the existing knowledge and learn from the environment. To handle such issues the researcher incorporated single case to dynamically update the existing fact in working memory.

- The system adds value in the domain area. Therefore, the application of new technology simplifies the working environment in the domain area. In addition the system also can reduce the burden of human expert by saving their time and energy spent while referring books and other manuals to solve the problems.

The system evaluators also provided their suggestions and comments on the weakness and strength of the knowledge based system. According to the system evaluators the following are some of the basic limitations of SLCTES:

- Cannot make creative and intelligent responses as human expert

- Lacks robustness such as sense and response ability

- The system lack the incorporation of some basic task in troubleshooting processes such as physical inspection and screen display which is significant to make conclusion.

- The system interacts with the user using only 'yes' or 'no' replies. Therefore, it lacks some flexibility.

The system evaluators also forwarded their constructive feedback on the strength of the knowledge based system. The strong sides of the expert system are:

- Helps to diagnose problems in short time and solve shortage of manpower in the ICT sector.

- Consistent answers for repetitive decisions, processes and tasks

- More accurate and Easy to use

- Applicable anywhere, even at home we can advise ourselves by having the software

- Make the diagnosing processes more clear, by showing the steps and procedures carried out by domain expert.

As a result, the expert system has ability to assist human expert to provide a better computer troubleshooting service. Therefore, this system helps the general users to solve problems occurring in the computer system in their own instead of going to ICT technicians. In addition, the system provides first level problem solving technique in order to increase the quality of computer troubleshooting services. However, the system needs to be intelligent and learn automatically during users' request.

\section{CONCLUSION AND RECOMMENDATIONS}

The self learning computer troubleshooting expert system (SLCTES) was designed to assist ICT technicians and computer users to solve problems occurring in the computer system effectively 
and efficiently. The knowledge's of domain experts acquired through interview question and document analysis and observation was made when the technicians are troubleshooting problems in offices or laboratories. The acquired knowledge was modeled by using decision tree and represented by rule based mechanisms. The represented knowledge was implemented by using SWI Prolog and its performance was evaluated by experts in the ICT office of Addis Ababa University. The result of performance evaluation indicated the expert system is very good and have ability to support ICT technicians and computer users. The expert system should also further strengthen to include the knowledge acquired from physical inspection of the computer condition for better decision.

The scope of the expert system should be extended to incorporate other symptoms occurring in the computer system such as physical appearance of the device, sound emitting, LED light, BIOS message, POST (power on self test) and network problems occurring in the user's personal computer. Rule based system can handle any domain specific problem, if there is perfect knowledge. But, most of the time the causes from the computer and the user may not satisfy the conditions of the given rule. Therefore, if we want to conclude better solution based on the few respondents response, then it is better to apply case based techniques in the expert system. The challenge in developing knowledge based expert is the user interface which is not simple and easy to interact. Because the tool used to develop self learning computer troubleshooting expert used SWI Win prolog which uses yes and no response to communicate. To handle this challenge the tool with better user interaction is required.

\section{REFERENCES}

[1] A. D. M. Africa. "An Expert System Algorithm for Computer System Diagnostics." International Journal of Engineering (IJE), 5(5), PP. 435 -467, 2011.

[2] Wikipedia. "Expert System.” http://en.wikipedia.org/wiki/Expert_system, Nov. 22, 2014 [Dec. 05 , 2014].

[3] J. King. "Knowledge based system development tools." Artificial Intelligence, Scotland: University of Edinburgh, pp 1-10.

[4] S. Mandal , S. Chatterjee and B. Neogi. (2013) "Diagnosis and Troubleshooting of Computer Faults Based on Expert System And Artificial Intelligence." International Journal of Pure and Applied Mathematics.[online]. 83(5), pp. 717-729. Available: http://www.ijpam.eu [June, 2015].

[5] I. C. Cameron. "A Computer Troubleshooting Expert System To Aid Technical Support Representatives.” Master Theses, Algoma University College, Canada, 2005.

[6] Einollah pira, Mohammad Reza Miralvand and Fakhteh Soltani,(2014) "verification of confliction and Unreachability in rule-based expert Systems with model checking." International Journal of Artificial Intelligence \& Applications (IJAIA), 5(2), pp. 21-28.

[7] S. Manda, S. Chatterjee, B. Neogi. (2012) "Diagnosis and Troubleshooting of Computer Faults Based On Expert System and Artificial Intelligence." International Journal of Pure and Applied Mathematics, 83(5), pp.717-729.

[8] D. Zmaranda, H. Silaghi, G. Gabor, C. Vancea. (February, 2013). "Issues on Applying KnowledgeBased Techniques in Real-Time Control Systems." INT J COMPUT COMMUN.[online]. 8(1): pp.166-175. Available:http://univagora.ro/jour/index.php/ijccc/article/viewFile/181/pdf [Dec., 2, 2014].

[9] S. Russell and P. Norvig.(2010). Artificial Intelligence Modern Approach.(3rd edition). [online]. Available: www.pearsonhighered.com [Oct., 2015].

[10] Heijst. "Conceptual Modelling for Knowledge-Based Systems." Encyclopedia of Computer Science and Technology, Marce Dekker Inc., New York. 2006.

[11] M. Malhotra.(june, 2015) "Evolution of Knowledge Representation and Retrieval Techniques." I.J. Intelligent Systems and Applications. [online]. 2015(7), pp. 18-28. Available: 
International Journal of Artificial Intelligence \& Applications (IJAIA), Vol. 7, No. 1, January 2016

http://www.mecs-press.org/ijisa/ijisa-v7-n7/IJISA-V7-N7-3.pdf [Oct., 2015].

[12] P. P. Singh Tomar and P. K. Saxena. "Architecture for Medical Diagnosis Using Rule-Based Technique." The First International Conference on Interdisciplinary Research and Development, Dayalbagh Educational Institute, Thailand, 2011.

[13] J. Prentzas and L. Hatzilygerousdis.(May 2007). "Categorizing Approaches Combining Rule-Based and Case-Based." Expert System. [online]. 24(2), pp. 97-122. Available: http://onlinelibrary.wiley.com [Apr., 2015].

[14] I. Bichindaritz, E. Kansu and Keith M. Sullivan. "Integrating Case-Based Reasoning, Rule-Based Reasoning and Intelligent Information Retrieval for Medical Problem-Solving," AAAI Technical Report, Clinical Research Division, Fred Hutchinson Cancer Research Center, Washington, 1998.

[15] A. Ligeza. (2006). Logical Foundation for Rule-Based Systems.(2nd edition). [online]. 2. Available:file:///C:/Users/hp/Downloads/9783540291176-t1.pdf. [Jun., 23, 2015].

[16] Juan Fuente, A. A. , López Pérez, B. , Infante Hernández, G. and Cases Fernández, L. J. (2013). "Using rules to adapt applications for business models with high evolutionary rates." International Journal of Artificial Intelligence and Interactive Multimedia. [online]. 2(2). pp. 56- 62 Available: DOI: 10.9781/ijimai.2013.227. [May, 2, 2015].

[17] Mary Lou Maher, (1984) Tools and techniques for knowledge-based expert systems for engineering design, Technical Report [online]. Available:http://repository.cmu.edu/cgi/viewcontent.cgi?article. [sep. 23, 2015].

[18] Sylvester I. Ele and Adesola, W.A. (2013). "Design of Computer Fault Diagnosis and Troubleshooting System (CFDTS)." West African Journal of Industrial and Academic Research [online]. 9(1). Pp. 43-53. Available: file:///C:/Users/hp/Downloads/105725-286730-1-PB.pdf [Jan., $5,2015]$.

[19] J. S. Bennet. "DART:An Expert System for Computer Fault Diagnosis." Heuristic Programming Project, pp.843-8454, 1980.

[20] Akande Ruth, Amosa Babalola, Sobowale Adedayo and Hameed M.A. (2015). "Web based expert system for diagnosis and management of kidney diseases." International Journal of Current Research and Academic Review. [online]. 3(2). Pp. 9-19. Available: http://www.ijcrar.com/vol-3-2 [Jul., 1, 2015].

[21] Ben Khayut, Lina Fabri and Maya Abukhana, (2014) "Intelligent user interface in fuzzy environment." International Journal of Artificial Intelligence \& Applications (IJAIA), 5(1), pp. 63-78.

[22] Mária Pohronská (2012) "Implementing Embedded Expert Systems via Programmable Hardware." Information Sciences and Technologies Bulletin of the ACM Slovakia, 4(2), pp. 10-19.

[23] Piotr Golański1, Przemysław Mądrzycki, (2015) "Use of the expert methods in computer based maintenance support of the m-28 aircraft." Zeszyty naukowe akademi i marynarki wojennej scientific journal of polish naval academy, 2 (201), pp. 5-12.

[24] Y. Bassil. (2012) "Expert PC Troubleshooter With Fuzzy -Logic." International Journal of Artificial Intelligence \& Applications (IJAIA), 3(2), pp. 11-21.

[25] Chunquan L., Yang Zh. and Qun S. "Decision Tree for Dynamic and Uncertain Data Streams." 2nd Asian Conference on Machine Learning (ACML2010), Nov. 8-10, 2010, pp. 209-224.

\section{AUTHOR}

Amanuel Ayde Ergado, received his BSc in Information Studies from Jimma University, Ethiopia in 2010 and MSc in Information Science from Addis Ababa University, Ethiopia in 2014. Currently, he is Lecturer in the Department of Information Science in Jimma University, Ethiopia. His current research interests are in the areas of artificial intelligent systems, information management, knowledge management, data

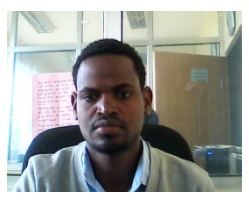
mining, database management systems and natural language processing. 